\title{
Evaluation of Antimicrobial Activities of Zirconium (IV) Complex
}

\author{
L. H. Mahind ${ }^{1}$, S.A Waghmode ${ }^{2}$, Avinash Nawale ${ }^{1}$, V. B. Mane ${ }^{1}$ and \\ S. P. Dagade*1 \\ ${ }^{1}$ Yashwantrao Mohite College, Bharati Vidyapeeth Deemed University, Pune-411038. Maharashtra, India. \\ ${ }^{2}$ Abasaheb Garware College, University of Pune, Pune, India
}

\begin{abstract}
In this proposal synthesis of a very simple Schiff base from substituted benzoic acid and substituted aldehyde and formed complex with transition metal such as zirconium (IV). The chemical structure of the synthesized metal ligand complex were confirmed by IR and elemental analysis. This complex showed the antimicrobial and antifungal activity and examined against different gram $+v e$ and $-v e$ bacteria and fungal strains.
\end{abstract}

Keywords: Antimicrobial, Antifungal activity; substituted aldehyde, Schiff base.

\section{Introduction}

The field of Schiff base complexes is fast developing because of the wide variety of possible structures for the ligands, depending on the aldehyde and amine used. Interest in transition metal complexes of these Schiff bases continues not only due to the interesting structural and bonding modes they possess, but also because of their various industrial applications [1].

Schiff bases, derived from o-hydroxy benzaldehyde have strong ability to form transition metal complexes [2-3]. The well-known transition metals form a series of coordination compounds with well defined structures [4-5]. It plays important roles in the numerous biological processes for the activation of some antitumor substances. In salens, the ligand acts as back bone and the coordinated metal ion can be easily varied which makes these catalysts especially useful in catalytic studies [6].

In our present study we have conducted antimicrobial activity against some microorganisms to see whether chelating agent and their metal chelates have any action on microbial activities using well diffusion method.

\section{Materials And Method}

All the chemicals and solvents used were of AR grade. Dimethylsulphoxide (DMSO), methanol and ethanol were purchased from sigma. The metal salts Zirconium Oxychloride $\left(\mathrm{ZrOCl}_{2} .8 \mathrm{H}_{2} \mathrm{O}\right)$ were purchased from commercial sources. The Antibacterial activity of synthesized Schiff base metal complexes was determined by well diffusion method using DMSO as a solvent control. The IR spectra were performed by a Nicolet iD5 FT-IR spectrophotometer in the range $4000-400 \mathrm{~cm}^{-1}$ using $\mathrm{KBr}$ pellet technique and the microanalysis of $\mathrm{C}, \mathrm{H}$ and N were estimated by FLASH 1112 Series Elemental Analyser at IIT, Bombay.

\subsection{Synthesis of Schiff base Ligand:}

\section{Experimental}

The Schiff base was prepared by condensation of substituted aldehyde with substituted benzoic acid (molar ratio 1:1) in ethanol and the mixture was refluxed for half an hour on oil bath at $60^{\circ} \mathrm{C}$.The resulting solution was evaporated under vacuum to remove the solvent. The product was collected by filtration, washed with several times with ethanol and recrystallized from hot ethanol and dried under vacuum.

\subsection{General procedure for the preparation of metal complex:}

A mixture of dry ligand under investigation in $15 \mathrm{ml}$ methanol and amount of metal salts (molar ratio 2:1) $\left(\mathrm{MX}_{2}\right.$, where $\left.\mathrm{M}=\mathrm{Ti}, \mathrm{Zr} ; \mathrm{X}=\mathrm{Cl} / \mathrm{NO}_{3} / \mathrm{Acetate}\right)$ were refluxed for one hour at $60^{\circ} \mathrm{C}$ on oil bath. On cooling, coloured solid product was collected by filtration; wash several times with hot ethanol until washing becomes colours. The product was dried in air and stored in desiccator over anhydrous $\mathrm{CaCl}_{2}$ under vacuum. The prepared metal complex was coloured and stable to air and moisture.

Antibacterial activity was determined by well diffusion method. The determination of the antimicrobial activity of the ligand and of the complex was carried out on samples of bacterial species. The test ligands and their metal complexes were dissolved in DMSO at a different concentration. The solvent control (only DMSO) was also maintained throughout the experiment. 


\section{Characterization}

The $\mathrm{Zr}$ complex is stable at room temperature. These are insoluble in water but soluble in DMSO solvent. However, the analytical, spectroscopic data enabled the prediction of the possible structure of the synthesized complexes. Moisture content of the samples was determined by using Karl Fischer instrument which indicates the sample indicate that samples are hygroscopic in nature. The analytic and physical properties of the ligand and $\mathrm{Zr}$ complex are summarized in below Table 1 .

Table 1: Analytical data and physical properties of the Schiff base ligand and its complex.

\begin{tabular}{|l|l|l|l|c|c|c|c|c|}
\hline Compound & Empirical & Colour & M.P. & \multirow{2}{*}{$\begin{array}{c}\text { Water content } \\
\text { formula }\end{array}$} & & & \multicolumn{4}{|c|}{ Elements found (calc.) } \\
\cline { 5 - 9 } & & & & $\mathbf{C}$ & $\mathbf{H}$ & $\mathbf{O}$ & $\mathbf{N}$ \\
\hline Ligand & {$\left[\mathrm{C}_{14} \mathrm{H}_{11} \mathrm{NO}_{3}\right]$} & Pale & $235^{\circ} \mathrm{C}$ & $0.55 \%$ & 69.60 & 4.63 & 6.50 & 69.60 \\
& & Yellow & & & $(68.29)$ & $(4.47)$ & $(5.69)$ & $(68.29)$ \\
\hline $\mathrm{Zr}(\mathrm{IV})$ & {$\left[\mathrm{ZrC}_{14} \mathrm{H}_{17} \mathrm{NO}_{7}\right]$} & Orange & $239^{\circ} \mathrm{C}$ & $1.11 \%$ & 47.87 & 4.07 & 4.61 & 47.87 \\
$\begin{array}{l}\text { Schiff Base } \\
\text { Complex }\end{array}$ & & & & & $(43.72)$ & $(3.90)$ & $(3.64)$ & $(43.72)$ \\
\hline
\end{tabular}

Table 2: IR spectral data of the Schiff base ligand and its complex.

\begin{tabular}{|c|c|c|c|c|c|}
\hline Compound & $\begin{array}{c}\mathbf{v O H} / \mathbf{H}_{\mathbf{O}} \mathbf{O} \\
\left(\mathrm{cm}^{-1}\right)\end{array}$ & $\begin{array}{c}\mathbf{v C}=\mathbf{N} \\
\left(\mathrm{cm}^{-1}\right)\end{array}$ & $\begin{array}{c}\mathbf{v} \mathbf{C}-\mathbf{O} \\
\left(\mathrm{cm}^{-1}\right)\end{array}$ & $\begin{array}{c}\mathbf{v C}=\mathbf{O} \\
\left(\mathrm{cm}^{-1}\right)\end{array}$ & $\begin{array}{c}\mathbf{v M}-\mathbf{N} \\
\left(\mathrm{cm}^{-1}\right)\end{array}$ \\
\hline Ligand & 3471.53 & 1569.80 & 1246.50 & 1618.02 & - \\
\hline $\begin{array}{c}\mathrm{Zr}(\mathrm{IV}) \text { Schiff Base } \\
\text { Complex }\end{array}$ & 3332.26 & 1628.12 & 1281.34 & 1628.12 & 456.30 \\
\hline
\end{tabular}

\subsection{Elemental analysis}

It is clear from the above data that the experimental values shown for each of the compound are good agreement with the theoretical values calculated for 1:1 ratio. The composition assigned to the ligand and its complex may therefore be formulated as presented in the Table 1 .

\subsection{Infrared Spectra}

In order to obtain more details on the structure of complex the IR spectra of complex has been measured and compared with the spectra of the ligand and their assignments are listed in Table 2. It indicates that formation of M-N co-ordination bond by showing the value at $456.30 \mathrm{~cm}^{-1}$.

\subsection{Test organism:}

The bacterial species Escherichia coli, Salmonella typhii, Staphylococcus aureus and Bacillus subtilis and fungal species Aspergillus niger were used as a test organism and bacterial culture they were maintained on Soybean- Casein Digest Agar (SCDA) and fungal culture Sabourands's dextrose (SDA) agar media.

\subsection{Assay of antimicrobial activity}

Well diffusion method was carried out to evaluate the antimicrobial activity of the synthesized $\mathrm{Zr}$ complex. The plates were incubated at $30-35^{\circ} \mathrm{C}$ for $24 \mathrm{hrs}$. During which activity was evidenced by the presence of a zone of inhibition surrounding the well. Antimicrobial and antifungal activity was observed in diameter of inhibition zones $(\mathrm{mm})$.

\subsection{Media:}

SCDA and SDA agar were used and was prepared in distilled water. The composition of media was as given below

Soybean- Casein Digest Agar (SCDA)

\begin{tabular}{|c|c|c|}
\hline 1. & Pancreatic Digest of casein & : $15.0 \mathrm{gm}$ \\
\hline 2. & Papaic Digest of soybean & $5.0 \mathrm{gm}$ \\
\hline 3. & Sodium chloride & $5.0 \mathrm{gm}$ \\
\hline 4. & Agar & $: \quad 15.0 \mathrm{gm}$ \\
\hline
\end{tabular}



5. Distilled water
$1000 \mathrm{ml}$
6. $\mathrm{pH}$
$7.3 \pm 0.2$

Sabourands's dextrose (SDA) agar

$\begin{array}{lll}\text { 1. } & \text { Dextrose } & \text { Mixture of peptic Digest of animal Tissue and } \\ \text { 2. } & & \\ & \text { Pancreatic Digest of casein(1:1) } & \mathrm{gm} \\ \text { 3. } & \text { Agar } & : 10.0 \mathrm{gm} \\ \text { 4. } & \text { Distilled water } & : 15.0 \mathrm{gm} \\ \text { 5. } & \mathrm{pH} & : 500 \mathrm{ml} \\ \end{array}$

\subsection{Preparation of Media}

Agar medium was accurately weighed and suspended in $1000 \mathrm{ml}$ of purified water in a conical flask. It was heated on a water bath to dissolve the medium completely and autoclaved at $121^{\circ} \mathrm{C}$ temperature and $15 \mathrm{psi}$ pressure for 15 minutes.

\subsection{Experimental method}

SCDA and SDA were prepared with lawn culture using desired test organisms. Inoculated plates were kept aside for few minutes. Using well cutter single well was prepared by dipping well cutter in alcohol for sterilizations, using sterilized micropipette different concentration of complex solution was added in to each well and control were added.

After diffusion the plates were incubated at $30-35^{\circ} \mathrm{C}$ for $24 \mathrm{hr}$. After incubation the inhibition of zones was observed and results were recorded in Table 3.

Table: 3 Antimicrobial activity results of Zr-Complex

\begin{tabular}{|l|c|c|c|c|c|}
\hline \multirow{2}{*}{ Micro-organisms } & \multicolumn{5}{|c|}{ Zone of inhibition in $\mathrm{mm}$} \\
\cline { 2 - 6 } & $1 \mathrm{mg} / \mathrm{ml}$ & $2 \mathrm{mg} / \mathrm{ml}$ & $3 \mathrm{mg} / \mathrm{ml}$ & $4 \mathrm{mg} / \mathrm{ml}$ & $5 \mathrm{mg} / \mathrm{ml}$ \\
\hline Ligand & -- & -- & -- & -- & -- \\
\hline Escherichia coli & -- & -- & 7 & 10 & 19 \\
\hline Salmonella typhii & -- & -- & 7 & 12 & 20 \\
\hline Staphylococcus aureus & -- & -- & 6 & 12 & 18 \\
\hline Bacillus subtilis & -- & -- & 6 & 11 & 17 \\
\hline
\end{tabular}

\section{Results And Discussion}

The results of the Zr-complex showed in the Table 3, indicated that the Escherichia coli, Salmonella typhii, Staphylococcus aureus and Bacillus subtilis have zone of inhibition but absent in the ligand and control. Such increased activity of the metal chelates is due to the lipophilic nature of the metal ions in complex [7]. As the concentration increases, the activity of metal chelates also increases.

\section{Antifungal activity of $\mathbf{Z r}$-Complex and ligand:}

Fungal species Aspergillus niger were used and showed low fungal activity in complex and detailed study is under investigation.

\section{Conclusion}

$\mathrm{Zr}(\mathrm{IV})$ complex has been synthesized using the above Schiff base ligand and characterized by spectral and analytical data. The data concluded that the metal complex has higher antimicrobial activity than the ligand. $\mathrm{Zr}$-complex showed the maximum antimicrobial activity against Salmonella typhii and E. Coli, while less active against Bacillus subtilis and very low antifungal activity against A.niger, fungal species under investigation.

\section{Conflicts of interest}

All authors have none to declare.

\section{Acknowledgement}

The authors express their sincere Thanks to Dr. Shivajirao Kadam, Vice Chancellor, Bharati Vidyapeeth Deemed University and Prin. K. D. Jadhav, Yashwantrao Mohite College, Pune for their constant 
inspiration and valuable support. Author also thanks to Dr. V. V. Dhapte, Head, Department of Chemistry for their encouragement and providing research facilities.

\section{References:}

[1] Vine K.L., Locke J.M., Ranson M., Pyne S.G., Bremner J.B., In vitro cytotoxicity evaluation of some substituted Isatin derivatives. Bioorg. Med. Chem., 2007, 15, 931-938.

[2] Santha lakshmi, Syed Tajudeer and Kannappan Geetha, Studies on antimicrobial activities of Schiff base complex derived from Dapsone J. Pharmacy Research, 2011, 4(5)1531-1532.

[3] United States of Pharmacopeia , 2012,35<62>, 64.

[4] Ayakumarswamy B.H.M., Rahaman F., Revankar V.K. and Pai K.V., Synthesis, Characterization, Anti-Microbial and AntiInflammatory activity, Studies of Novel Schiff base 3,3'-\{1,2-PhenyleneBis [Nitrilo(E) Methylydine] $\}$ Diquinolin-2-ol and its Metal(II) Complexes, Intel J. of PharmTech Research, 2011, 3(3), 1864-1873.

[5] Jarrahpour A., Khalili D., Clercq De E., Salmi C., Brunel M. J.,Synthesis, antibacterial, antifungal and antiviral activity evaluation of some new bis-Schiff bases of Isatin and their derivatives, Molecules, 2007, 12, 1720-1730.

[6] S. Arunachalam, Padma priya, Jayabalakrishnan, and Chinnusamy, Ruthenium (II) schiff base: complexes, physico-chemical, Spectrometric, microbial and DNA binding and cleaving studies, Int. J. applied biology and pharma. tech., 2011, 2(3).

[7] Omar M. M., Mohamed G. G. and Hindy A. M. M., Transition metal complexes of heterocyclic schiff base Biological activity, spectroscopic and thermal characterization, Journal of Thermal Analysis and Calorimetry, 2006, 86 (2), 315-325 